\title{
LAS TRADICIONES ESPECULATIVAS DE LA SOCIOLOGIA DE LA MÚSICA Y LA ESTÉTICA *
}

\author{
Antonio Serravezza
}

Es indudable que la expresión «sociología de la música» se utiliza con excesiva amplitud. Si en el uso común prevaleciera una definición precisa y vinculante, y si la «sociología de la música» fuera una disciplina en sentido estricto, ciertamente amplios sectores de los estudios habitualmente abarcados por tal denominación se verían privados del derecho de hacerla propia. No sé si cabe auspiciar semejante hipótesis. Por una parte se introduciría un elemento de claridad terminológica. Pero por otra se abriría una cuestión nominalista ociosa, pues la heterogeneidad de los intereses y estudios que coexisten bajo esta denominación es evidente y no precisa de subrayados ulteriores.

Siempre se ha insistido en la distinción entre una sociología de la música de modelo empírico y otra de modelo teórico o especulativo. Sólo una referencia genérica común a la esfera de lo social justifica una misma denominación. En realidad, la diferencia de los ámbitos temáticos respectivos es evidente, como evidente es también la diferencia de «estilos científicos»: los modelos de cientificidad, o mejor aún la elección fundamental en el plano de los valores científicos, concurren a la creación de acentuados elementos distintivos en el interior de un sector aparentemente unitario. La divergencia de planteamiento también puede resultar radical, esto es, afectar a las propias raíces del trabajo de aquellos que se dedican a la «sociología de la música». Hay que preguntarse, pues, si ante tal heterogenei-

* Traducción de Alberto Clavería. 
dad tienen sentido las discusiones y polémicas que frecuentemente han afectado a los dos modelos fundamentales. En rigor, faltan los presupuestos para una confrontación, pues no subsisten elementos comparables seguros entre investigaciones sólo conjuntadas por la amplitud de las convenciones lingüísticas.

Por otra parte, la distinción entre un modelo «empírico» y un modelo «especulativo» no siempre da cuenta de las diferencias efectivas entre los diversos sectores. Hay a este respecto otros elementos caracterizadores, no coincidentes con esta bipartición, más no por ello menos decisivos. A este objeto quizá fuera útil señalar la estrechísima alianza establecida en ocasiones entre sociología de la música y estética o crítica musical. En otras palabras, sería oportuno tematizar una distinción entre una sociología de la música que persigue fines científicos autónomos y otra orientada hacia la crítica y la estética. Que posteriormente esta distinción resulte, de hecho, frecuentemente superponible a la distinción entre modelo teórico y modelo empírico, se debe a la circunstancia de que una predisposición o una disponibilidad a la alianza con la crítica musical y con la estética se encuentra más fácilmente en el campo de los estudios que ofrecen una "concepción» del enraizamiento social de la música. Pero esto no afecta al hecho de que en principio los dos aspectos se mantengan separados.

La predisposición al encuentro entre observación sociológica de la música e interpretación crítica es temprana. Ya hacia mediados del siglo pasado (aunque se trata sólo de un ejemplo) Wilhelm Heinrich Riehl introducía en su obra Musikalische Charakterköpfe ${ }^{1}$ un ensayo titulado Bach und Mendelssobn aus dem sozialen Gesicbtspunkt. La referencia a la dimensión de lo social, que no era nueva en los escritos sobre música, recibe aquí un significativo reconocimiento desde el momento en que es introducida como indicación explícita de una perspectiva fundamental adoptada en un ensayo crítico. Tras más de medio siglo, cuando al final de la época positivista Charles Lalo declara en su Esquisse d'une estbétique musicale scientifique que «el valor estético es un valor social», ${ }^{2}$ y que por tanto es inútil acercarse a la dimensión estética de la música con otras orientaciones, aunque sean científicas, que prescindan de la sociología, sus páginas señalarán un camino preciso: la sociología debe ocuparse no de la música tout court, sino de su dimensión estética. Esta dimensión, por ejemplo, es inaccesible a la psicología, la cual «nos conduce a los umbrales de la estética pero no nos ayuda a abarcarla». ${ }^{3}$ Del mismo modo es inadecuado

1. W. H. Riehl, Musikalische Charakterköpfe, Stuttgart, 1899 (octava edición).

2. Ch. Lalo, Equisse d'une esthétique musicale scientifique, Paxís, 1908, p. 29.

3. Ibidem. 
el intento de interpretar la música en su especificidad estética con el auxilio de metodologías sólo en apariencias sociológicas, como las de Taine o Guyau, porque no tematizan la verdadera naturaleza colectiva de los valores musicales. Serán las categorías de la sociología de Durkheim (que, dicho sea de paso, han dejado más de una huella en los escritos sobre música de aquellos años; baste con citar La musique, ses lois, son évolution, de Jules Combarieu, obra de la que hablaremos más adelante) las que permitan a Lalo la definición de la realidad estética de la música como un campo delimitado de valores colectivos, normas, instituciones y sistemas sancionadores. Lo estético y lo social, la estética y la sociología, se unen en una relación no externa $u$ ocasional, sino ligada a las propias raíces de los valores musicales. La referencia a lo social no suprime la dimensión estética, ni el tratamiento sociológico se propone como alternativa al estético (sucede lo contrario, por ejemplo, en las estéticas neoidealistas y espiritualistas de principios de siglo); más bien viene introducido en apoyo del estético. Más adecuadamente podría hablarse de un intento de defender, justificar y reforzar con instrumentos sociológicos una dimensión que por otra parte se considera afectada por una crisis de legitimidad. Ciertamente, todo esto se presenta en Lalo bajo el lema de un programa «científico», en la misma línea que las aspiraciones de la última generación positivista. Pero se mantiene el hecho de que la cientificidad del tratamiento sociológico desemboca en un programa esencialmente estético. Y la literatura crítico-musical de aquellos años, en mayor medida que la de los precedentes, presenta numerosas referencias a la realidad, por alejadas que estén, en calidad e interés, de las correspondientes a la posterior y refinada crítica sociológica de Adorno.

Ciertas páginas del padre fundador de la musicología francesa, Jules Combarieu, son un ejemplo de la renovación del panorama crítico efectuado con ayuda de la sociología. En un párrafo de su ensayo La musique, ses lois, son évolution, ${ }^{4}$ propone un Analyse de la sonate de J. S. Bach en la mineur, au point de vue sociologique. Se trata de un breve ensayo en el que se explora una sonata de Bach (que en realidad es de atribución dudosa) especialmente en su perfil morfológico y estilístico, con cierto número de referencias a la historia social. El objetivo de este estudio, propuesto por el propio Combarieu como ejemplo de una nueva metodología, es demostrar la multiplicidad de las relaciones entre realidad social y realidad musical que pueden determinar el sentido de una obra. Pero el caso de Combarieu es notable también en otro aspecto. A pesar de sus aperturas sociológicas, polemiza contra cualquier interpretación à coté, muestra su

4. J. Combarieu, La musique, ses lois, son évolution, París, 1907. 
preocupación por salvaguardar lo «específico musical», teoriza un «pensamiento musical» totalmente autónomo y subraya con insistencia la irreductibilidad del lenguaje musical a otros modelos de comunicación. En ocasiones el lector se ve inclinado a situarlo en la misma línea que el formalismo hanslickiano. Al mismo tiempo, la música aparece en su libro como un fenómeno con varios sentidos y en consecuencia su interpretación es confiada a una serie de disciplinas como la acústica, la fisiología, la matemática, la estética y la sociología. Así pues, el tratamiento autónomamente estético no pretende agotar el significado del objeto musical, «tan complejo y rico en sentidos». ${ }^{5} Y$, de hecho, la sociología, entre los demás tratamientos, conquista un papel de gran relevancia. Así, se confunden razones de la autonomía y razones de la heteronomía en un contexto que quisiera conciliar exigencias distintas y contrastadas. ¿Debilidad teórica de Combarieu? Tal diagnóstico sería demasiado fácil, incluso trivial. El problema es enfocar las razones de esta ambivalencia.

Combarieu se mueve en una frontera que divide regiones distintas y potencialmente hostiles. Las frecuentes incursiones en uno u otro campo (desde la identidad estética irreductible de la música hasta el Analyse au point de vue sociologique y viceversa) nacen de su contiguiidad. Ambas están presentes, cada una con sus exigencias específicas, en la conciencia teórica de Combarieu. Lo que superficialmente puede parecer incoherencia es en realidad signo de una crisis, de una situación problemática intensamente vivida pero irresuelta. $\mathrm{Y}$ también es signo de una posición teórica adelantada, pues no está cerrada en el horizonte de una estética tradicional, sino abierta a las aportaciones de nuevas ciencias, entre ellas la sociología. Cuando Combarieu sitúa simplemente la estética entre las demás disciplinas que pueden dar un sentido a la música, efectivamente está prefigurando una nueva estética, en la cual los tratamientos particulares concretos se integran en un diseño articulado sobre una pluralidad de planos. En este diseño la sociología es un instrumento esencial, si bien no representa un terreno autónomo de indagación: sirve para explorar los sentidos de la música, para dar significado a una clase de objetos de relevancia estética imprescindible. Como en el caso del Analyse, la sociología sirve para penetrar en el mundo de la obra, e incluso en las dimensiones más escondidas de este mundo, como la morfológica, y para revelar en ella aspectos esenciales. El lema parece ser renovación, más que alternativa. No se trata de modificar radicalmente los estatutos de los estudios musicales y de la cultura musical; no se trata de derribar viejos planteamientos; se trata más bien de que conviven viejas exigencias y nuevas instancias en un horizonte

5. Op. cit., p. 3.

s. 
más vasto y comprensivo. La sociología no es un nuevo paradigma científico destinado a destruir antiguas convicciones, sino un instrumento llamado a cooperar en el proyecto de dar un sentido a la música. Tal es, en el fondo, el significado del ensayo de Combarieu: indicio de una situación en que se mezclan voluntad de no dar la espalda a un mundo tradicional de valores y sentimiento de insatisfacción por el viejo mundo. Una situación teórica que, como decíamos, evidencia la inserción de la sociología de la música en un territorio fronterizo.

Nos hemos entretenido en las posiciones de Combarieu porque de algún modo pueden ser leídas como prefiguraciones remotas de una problemática que hallará expresión mucho más amplia en la obra de Th. W. Adorno. A primera vista, el acercamiento de estos dos nombres puede suscitar perplejidad, especialmente si se considera que el autor de La musique, ses lois, son évolution se sitúa, a pesar de todo, en una área tardopositivista lejanísima, y no sólo históricamente, de la «dialéctica negativa».

En realidad, también en Adorno se vuelve a presentar la cuestión de la alianza entre sociología, estética y crítica musical. Conviene observar el hecho de que frecuentemente las bibliografías de sociología de la música acogen su Filosofía de la música moderna. ¿Qué derecho tiene semejante obra a ser incluida en el área de que estamos tratando? El libro propone una perspectiva de ciertos sectores de la llamada «vanguardia histórica», con numerosas referencias a una imagen abarcadora del mundo contemporáneo. La relación entre vanguardia y realidad contemporánea sería interpretada como homología, cotejo ideológico, o como oposición, rechazo, o eventualmente como complejo cruce dialéctico entre ambas dimensiones. En este vasto diseño interpretativo encuentra lugar ocasionalmente un lenguaje sociologizante («soledad colectiva», «división del trabajo», etc.), y, por otra parte, la imagen del mundo contemporáneo que se propone presenta notables valores e implicaciones sociológicos.

Pero el objetivo del libro no es verificar estos nexos en cuanto tales, sino en tanto que reveladores del significado de importantes sectores de la producción musical y del repertorio. En otras palabras, el discurso finaliza con la exploración del sentido de la Neue Musik, que sólo se considera adecuadamente comprensible por referencia a la realidad que es su fondo. Adecuadamente comprensible, esto es, captable de forma perspicua y en aspectos esenciales, que de otro modo estarían destinados a permanecer en la sombra. La referencia a una imagen del mundo, y a los aspectos sociales que concurren a definirla, termina con la construcción de una esfera de significados estéticos o con su aclaración; en una palabra, con la crítica musical. La sociología - el uso de la palabra supone una vez más contraer una deuda de gratitud respecto a la amplitud terminológica de la que se 
ha hablado - se somete a finalidades críticas, se vuelve instrumento de una hermenéutica que interroga el sentido de la música de los primeros decenios de nuestro siglo. En qué medida ha tenido éxito la operación es cosa que escapa a los límites de nuestra discusión. Con todo, habrá que admitir que sea cual fuere la valoración que de ella se haga, la interpretación en clave sociológica del expresionismo, de la dodecafonía y del neoclasicismo propuesta por Adorno, ha acabado por constituir más que una interpretación, ha terminado por asociarse en una unidad de sentido a tales producciones, a convertirse en un pendent insoslayable.

Así como la crítica musical se dirige de modo privilegiado a los objetos cuyo sentido no viene dado de manera pacífica y estable, sino a aquellos en los que éste está oscurecido en alguna medida y requiere una intervención explicativa y clarificadora, es evidente que los objetos de los que se ocupa la Filosofía de la música moderna necesitan el máximo de oxígeno crítico. $\mathrm{Y}$ es por ello comprensible que terminen asociándose a sus interpretaciones, constituyendo unidades culturales complejas, y que las interpretaciones se conviertan en integraciones casi constitutivas, en una simbiosis de sonido musical y palabra crítica. Lo que da valor a nuestra reflexión es que, en el caso en cuestión, la palabra crítica que se asocia al objeto tiene valores sociológicos. A pesar del proclamado «aislamiento» de las vanguardias, la esfera de lo social se hace explicativa respecto del sentido del objeto musical. Añádase que en Adorno la interpretación sociológica de las vanguardias no se basa en datos de hecho, en circunstancias empíricamente comprobables. Él nos advierte de que «las formas del arte registran la historia de la humanidad con mayor exactitud que los documentos», ${ }^{6}$ por más que no exista un fundamento documental de las tesis sobre los nexos que ligan el sentido de las vanguardias musicales con el mundo contemporáneo. Desde este punto de vista, la Filosofía de la música moderna prefigura la posición de Adorno en el ámbito del Positivismusstreit: la teoría reivindica una legitimidad autónoma respecto del «hecho» y contrapone al «fetichismo del dato» las propias certezas apodícticas. $\mathrm{La}$ crítica musical puede hallar afinidades electivas en la sociología si ésta es teoría, si ofrece una concepción.

Adorno escribe en la Introducción a la sociología de la música: "Cuanto más ciertas son las observaciones sociológicas sobre la música, tanto más lejanas y ajenas son a ésta. Pero cuanto más profundamente se hunden en los nexos específicamente musicales, tanto más amenazan con convertirse

6. Th. W. Adarno, Pbilosopbie der neuen Musik, trad. ital. Filosofia della musica moderna, Turín, 1959, p. 49 (existe trad. castellana: Filosofía de la nueva música, Buenos Aires, Sur, 1966). 
en pobres y abstractas desde el punto de vista sociológico.» ${ }^{7}$ La certidumbre (en el sentido de objetividad factual) es inversamente proporcional al interés. En la medida en que la sociología de la música apunta a lo concreto, al nivel de los hechos, a lo empíricamente comprobable, deja escapar lo «específicamente musical». De modo que la alternativa con que se encuentra la investigación es la que se plantea entre un rigor incapaz de captar la realidad musical y un conocimiento profundo de los significados musicales, carente de rigor empírico. En cualquier caso, este último no es garantía de valor cognoscitivo: la sociología de la música puede provechosamente basarse en formas de conocimiento «desde dentro», próximas a la Versteben historicista, las cuales están capacitadas para superar el nivel de la comprobación y de la verificación empíricas. No debe pretenderse «demostrar más allá de cualquier duda que la música de Beethoven tenía realmente algo que ver con la bumanitas y el movimiento de emancipación burgués, o la de Debussy con la manera de ver la vida que tenían el impresionismo y la filosofía de Bergson. Hechos sumamente plausibles se convierten, por la endurecida mentalidad científica, cuyo etbos consiste en querer ser ciego respecto a la experiencia de los objetos y estudiar de ellos solamente los reflejos que nos llegan, en dogma especulativo [...] El espíritu, que mora en los objetos de las ciencias del espíritu, se convierte en acusado frente a los procedimientos en que éstas han degenerado, y para los cuales poder demostrar a todos los resultados conseguidos es más importante que explicar la cosa a través de ellos». ${ }^{8}$ Así como el rigor empírico es una forma de ceguera, existe sin embargo una evidencia indiscutible que garantiza los «hechos sumamente plausibles» que se desvelan a los ojos de quien sabe observar la música «desde dentro» (y que no son «hechos» en el sentido positivista). Ahora bien, la alternativa metodológica procede de otra alternativa que representa la clave de bóveda del edificio adorniano y que se refiere al objeto de la investigación. La música puede ser realidad autónoma estética, entidad dotada por sí misma de significado o elemento incluido en un contexto relacional, en una circunstancia de producción, comunicación, recepción y consumo. Sólo en el primer caso le atribuye Adorno un «contenido inmanente de verdad»; los demás aspectos son simples epifenómenos, irrelevantes para un estudio que busque la confrontación con la «cosa misma». Y esta última, precisamente en su autonomía, en su inmanencia, acoge un elemento social. No se trata de un dato externo, de un rol funcional o de cualquier cosa semejante, sino de un momento

7. Th. W. Adorno, Einleitung in die Musiksoziologie. Zwölf theoretische Vorlesungen (trad. ital. Introduzione alla sociologia della musica, Tutín, 1971, p. 238).

8. Op. cit., pp. 237.238. 
esencial del significado, de la «constitución social objetiva de la música en sím. ${ }^{9} \mathrm{La}$ alianza entre sociología, interpretación crítica y estética, es una necesidad impuesta por este estatuto particular de la obra musical. «Los problemas estéticos y sociológicos de la música están entrelazados entre sí indisoluble y constitutivamente.» ${ }^{10}$ Además, "el nivel estético y el contenido de verdad del producto mismo mantienen una estrecha interacción, por más que uno y otro no sean ciertamente idénticos entre sí. Nada vale estéticamente en música que no sea también socialmente verdadero, aunque sólo sea como negación de lo no verdadero, y ningún contenido social de la música vale si no se objetiva estéticamente». ${ }^{1}$

Semejante concepción requiere arduos ejercicios de equilibrismo teórico. La no fácil empresa de salvaguardar la autonomía estética de la obra musical, cerrada en sí misma, en su inmanencia, al mismo tiempo que se pone en relación con la vida social y sus dinámicas, sugiere a Adorno una imagen con frecuencia presente en sus páginas: la de la mónada, entidad autónoma y microcosmos cerrado, pero inscrita al mismo tiempo en una vicisitud plena, de la cual, aunque esté aislada, lleva signos en su interior. ¿Qué exigencia producen estas concepciones? Se propone aquí nuevamente una hipótesis ya formulada respecto a Combarieu. Es evidente la relación con la esfera del valor estético, con la idea de que la música se da esencialmente en la dimensión de la «obra», del objeto artístico. ${ }^{12}$ Adorno ve en la tradición de la música occidental una suma de valores estéticos y declara su fidelidad a este campo, el campo de la «gran música». Quiere además excluir cualquier condicionamiento social inmediato, porque el compromiso directo de la música en el terreno factual de los fenómenos sociales perjudicaría su autonomía estética. Por otra parte, advierte la insuficiencia de una interpretación que excluya cualquier referencia a lo social. Defender la autonomía de la intromisión de elementos externos no excluye la presencia en el significado de la obra de aspectos con ellos relacionados. Es posible una conciliación de los dos elementos a condición de que lo social pierda el carácter de «dato» externo para volverse consustancial a la obra. Por otra parte, produciría extravío ignorar esta dimensión, pues el «espíritu objetivo» que da sustancia a la música tiene un aspecto social imprescindible. La religión romántica del arte o las estéticas idealistas que ignoran este plano imposibilitan una relación acertada con la música. Según escribe Adorno en su Teoría estética, ninguna obra «es comprensible como procedente puramen-

9. Op. cit., p. 240.

10. Ibidem.

11. Ibidem.

12. Cf.H.H. Eggebrecht, «Grenzen der Musikästhetik?, en Musikaliscbes Denken, Wilhelmshaven, 1977, pp. 212-215. 
te de su interior. Todas ellas son tanto una construcción en sí plenamente formada, con una lógica propia y unas consecuencias propias, como momentos del nexo entre espíritu y sociedad [...] Si bien el modelo de la comprensión estética es la expresión que aparece en la obra; si bien la comprensión se pone en peligro en cuanto la conciencia se desvía de aquella zona; por otra parte, no obstante, debe mantenerse en movimiento pese a la resistencia a que se ve expuesta tal movilidad del pensamiento. A quien está solamente dentro, el arte no le abre los ojos; quien está solamente fuera, distorsiona las obras de arte con su falta de afinidad». ${ }^{13}$

La idea de una sociología de la música como sociología del objeto musical se une a esta compleja situación teórica. En sustancia, se trata de una hermenéutica cuyo papel, como se ha señalado, es abrir a la comprensión el significado de la música y de las obras singulares. Tal significado es objetivo, no porque sea objetivamente verificable en sentido científico, sino porque se le cree radicado «en la cosa misma». Ciertamente, la sociología del objeto musical no agota el campo de la sociología de la música. Junto a ella hay otra que podriamos definir como una sociología de las funciones musicales, la cual se ocupa de las vicisitudes «externas» en que está implicada. Pero ya se ha dicho que Adorno tiende a asimilar esta "segunda» sociología a una estética negativa y a concebirla como análisis de los procesos de degradación o decadencia que el significado originario o inmanente de la obra padece en la vicisitud de los eventos sociales. El término «auténtico» no agradaba al autor de la Filosofía de la música moderna. Y sin embargo es difícil evitat su uso si se quiere dibujar el panotama de su sociología especulativa, alimentada precisamente por la fe en la «autenticidad» de un significado estético incorrupto de la música y de la denuncia, más moralista que política, de la degradación del arte en un mundo alienado. En cualquier caso, la relación música-sociedad se halla en el centro de un juego complejo: por una parte, el elemento social heterónomo viene subsumido en la esfera de la autonomía según un esquema monadológico que permite a la música conservar la propia identidad estética, precisamente relacionándose con lo social; por otra, el arte autónomo corre el riesgo de verse comprometido en procesos sociales que lo degradan obligándole a asumir la «función de lo que no tiene funciones».

Lo que era en Combarieu problemática irresuelta, oscilante, entre los polos de la autonomía y de la heteronomía, se convierte aquí en dialéctica compleja. Pero se mantiene un elemento común, cual es la experiencia del limite. Un mundo de valores se considera insuficiente; en la dimensión de

13. Th. W. Adorno, Ästbetiscbe Tbeorie; trad. ital. Teoria estetica, Turín, p. 496 (existe trad. castellana: Teoría estética, Madrid, Taurus, 1971). 
lo social se busca un sentido suplementario que atribuir al objeto-música, y en la sociología una integración indispensable de los estudios musicales. Al mismo tiempo, el nuevo instrumento no es radicalizado en su uso ni es considerado alternativo respecto al planteamiento estético del arte musical, cuya autonomía, por lo demás, se salva. Pero en Adorno la experiencia del limite se configura también en otro significado. La apertura a la dimensión de lo social, en teoría, no llega hasta el punto en que podría amenazar la identidad cultural de quien reconoce en la «gran música» su propio horizonte axiológico. El mundo de la comunicación y de la reproducción musical, y los fenómenos de masas que afectan a la música, no se indagan con genuinas intenciones cognoscitivas como ottos aspectos de la cultura musical, sino que son conducidos hacia la periferia del interés sociológico, que sustancialmente se circunscribiría a la hermenéutica social de la «gran música». Así pues, la sociología de la música no se sitúa solamente en la frontera entre autonomía y heteronomía, sino también en aquella que separa la tradición de la música artística (entendida en un sentido acentuadamente selectivo, con evidentes pretensiones de aristocracia intelectual) de todas las demás experiencias ajenas a ella, especialmente las ligadas a la esfera del «consumo».

Los textos de Adorno ilustran de modo ejemplar la dialéctica entre significado social y significado estético de la música, entre interpretación sociológica e interpretación crítica. Ahora bien, no debe pensarse que el contacto entre estas perspectivas tenga lugar solamente en sus páginas o en unos pocos precedentes. En realidad, puede encontrarse cierta vocación crítica, o tal vez una simple potencialidad crítico-estética en otros sectores de la sociología de la música, y en ocasiones incluso en los aparentemente más ajenos a problemáticas de este tipo. Del mismo modo, la posición teórica que hemos definido como experiencia del limite, y que hemos individuado en la raíz de este modelo de sociología de la música, también es observable en textos muy apartados del planteamiento adorniano.

Piénsese a este respecto en «Los fundamentos racionales y sociológicos de la música» de Max Weber. ${ }^{14}$ Este ensayo es citado con frecuencia como modelo de rigor científico alternativo a la sociología de la música de tipo «especulativo». En ocasiones, también se presenta paradójicamente mezclado con los estudios de planteamiento «positivista». Efectivamente, las páginas de Max Weber son ricas en datos y elementos objetivos. A veces

14. M. Weber, Die rationalen und soziologiscben Grundlagen der Musik, trad. ital. «I fondamenti razionali e sociologici della musica», en Economia e societd, Milán, 1980 , vol. v (existe trad. castellana: «Los fundamentos racionales y sociológicos de la música», en Economía y Sociedad, México, FCE, 1964, vol. II). 
es casi sorprendente ver cómo domina los conocimientos más actualizados de su época en materias como historia de la música, teoría musical, acústica, organología y etnomusicología. Posteriormente, la impresión de tigor científico es confirmada por el método comparativo, el cual hace surgir aspectos originales y elementos constantes de las diversas culturas musicales reseñadas.

Mas el significado de "Los fundamentos...» no se agota en el plano del rigor y del cientifismo empírico. En el fondo, Max Weber intenta precisar la especificidad, esto es, los caracteres originales de la cultura musical del Occidente moderno; y el método comparativo tiene por objeto la investigación de tal especificidad. Se trata también de llevar a cabo en el campo de la música la indagación que en otros campos ha llevado a individuar el quid especial del Occidente moderno en un sistema económico particular, en valores éticos particulares, en modelos jurídicos e institucionales particulares, y así sucesivamente. Ya en las primeras páginas de La ética protestante y el espiritu del capitalismo se citaba el proyecto de un mapa de esta cultura, incluyendo también los aspectos musicales. En una larga lista de realizaciones, que «solamente Occidente» ha sabido llevar a cabo, se lee lo siguiente: «El oído musical parece haber estado más desarrollado en otros pueblos de lo que lo está hoy día entre nosotros; en cualquier caso, no menos. Diversos tipos de polifonía han estado ampliamente difundidos por todo el mundo; también el discanto se halla en otros países. Del mismo modo, en otros países se conocen y se calculan todos nuestros intervalos sonoros racionales. Pero la música racional, tanto de contrapunto como armónica en sentido estricto; la estructura del material sonoro sobre la base de los tres acordes perfectos con la integración armónica de la tercera; nuestro cromatismo y nuestra armonía, expresados a partir del Renacimiento no como medida de distancia, sino de forma racionalmente armónica; nuestra orquesta con el cuarteto de cuerda como núcleo central y con su organización del conjunto de instrumentos de viento; el bajo de acompañamiento; nuestra notación musical (la única que hace posible la composición y ejecución de las obras musicales modernas, esto es, su duración en el tiempo); nuestras sonatas, sinfonías y óperas, aun cuando en las músicas más diversas existan como medios de expresión; la música programática, la música descriptiva, la alteración de los tonos y la modificación, y como medio para éstas, nuestros instrumentos fundamentales: órgano, piano y violín; todo esto es propio solamente de Occidente.» ${ }^{15}$

15. M. Weber, Die protestantiscbe Etbik und der Geist der Kapitalismus, trad. ital. L'etica protestante e lo spirito del capitalismo, Florencia, 1965, pp. $64-65$ (existe trad. castellana: La ética protestante y el espiritu del capitalismo, Barcelona, Peninsula, 1973). 
El mismo problema reaparece en un ensayo metodológico fundamental, El significado de la «neutralidad valorativa» para las ciencias sociológicas y económicas. Se trata de un planteamiento muy interesante, pues en tal contexto metodológico el problema de la especificidad de la cultura musical de Occidente recibe una nueva luz. Tras afirmar que la sociología del arte agota «su competencia meramente empírica» con el análisis de los factores técnicos objetivos de la producción artística, sin adentrarse en cuestiones de valor estético, observa que para esta disciplina «el interés por las obras de arte y sus propiedades particulares de relevancia estética, y por tanto su objeto, es [...] heterónomo, un a priori que aquélla, con sus medios, no puede de hecho establecer». ${ }^{16} \mathrm{Y}$ dice también: «La dirección del interés, esto es, el objeto a explicar históricamente, viene dado por la historia de la música heterónomamente, a través de su relevancia estética.» ${ }^{17}$ En otras palabras, los estudios históricos y sociológicos, «libres de valores» en su desarrollo y en su lógica interna, presuponen un elemento de valor en la elección del campo, si bien la neutralidad metodológica opera en un ámbito temático condicionado por orientaciones valorativas. Así se explica la razón que indujo a Max Weber a precisar que los problemas de sociología de la música antes mencionados lo son «desde el punto de vista del interés del bombre europeo moderno" y a subrayar con un signo de exclamación que tal perspectiva representa «una referencia a valores». ${ }^{18} \mathrm{Al}$ subrayar el cientifismo de la construcción weberiana garantizada por el postulado de la Wertfreibeit no debe olvidarse este aspecto, so pena de una inaceptable simplificación del problema. La admisión del «interés» y de la elección de valor que figuran entre las condiciones previas del trabajo científico, si bien por una parte contribuye a individuar diversos momentos de la investigación, y por tanto a evitar confusiones de jerarquía; por otro lado, no permite demarcar en ella una ciudadela cerrada.

Los fundamentos racionales y sociológicos de la música son considerados desde este punto de vista. Max Weber efectúa a este respecto un amplio reconocimiento de innumerables aspectos «técnicos» de la música, absteniéndose de cualquier intervención estética y valorativa. Analiza la evolución de los materiales sonoros y su sistematización teórica en diversas culturas europeas y extraeuropeas, con una óptica tanto diacrónica como sincrónica. De este reconocimiento de amplio radio emerge, documentada y

16. M. Weber, «Der Sinn der "Wertfreiheit" der soziologischen und ökonomischen Wissenschaften», en Gesammelte Aufsätze zur Wissenscbaftslebre, Tübingen, 1951, p. 507 (existe trad. castellana en Sobre la teoría de las ciencias sociales, Barcelona, Península, 1971).

17. Op. cit., p. 509.

18. Op. cit., p. 507. 
objetiva, la originalidad de la civilización musical del Occidente moderno. Se trata de una especificidad ligada a un referente sociológico preciso: la $Z$ weckrationalität, es decir, la actitud racional respecto del objetivo, que en nuestra cultura es guía tanto de la teoría y la práctica musical como de las demás artes, de la economía, del poder público, etc. Semejante modelo de actuación social propicia el nacimiento de la armonía tonal, de determinados instrumentos musicales, de un sistema de notación íntegramente racional y del temperamento equitativo. Este último representa una meta particularmente significativa del proceso «tacional» de la música, en tanto que en él, «junto a la medida de los intervalos según las distancias, se halla la concepción de los intervalos según los acordes armónicos» ${ }^{19}$ que, conforme a los ideales de la Zweckrationalität, libera innúmeras posibilidades y resulta muy «funcional» y «económico». De ello proviene la conquista de una superioridad técnica, que no estética, de la cultura musical de Occidente.

Pero, ¿hasta qué punto es posible atenerse a una separación tan rigurosa entre la dimensión estética y la técnica? Al parecer, Max Weber tuvo ocasión de documentarse incluso escuchando grabaciones de cantos primitivos reunidos en el Phonogramm-Archiv de Berlín, creado por Carl Stumpf y Eric von Hornbostel. ${ }^{20}$ Pero esta documentación se inscribe en un contexto no coincidente con las perspectivas de los fundadores de la escuela etnomusicológica de Berlín. En un trabajo Sobre el significado de las investigaciones etnológicas para la psicología y la estética musical, Stumpf, por ejemplo, afirmaba que esta última «estará construida sobre cimientos inseguros si cree poder sustraerse a un estudio en profundidad de las variedades étnicas. Para la estética musical tal estudio es tan necesario como el de la evolución histórica, y las dos clases de hechos [...] deben correlacionarse de modo estrechamente recíproco. Hasta la vieja estética especulativo-deductiva de cuño hegeliano era en este sentido de perspectivas más amplias y liberales de lo que hasta el momento ha mostrado ser la estética experimental, pues por lo menos intentaba acoger en sí el devenir histórico». ${ }^{21}$ En otras palabras, la etnomusicología tendría que eliminar cualquier

19. Max Weber, Die rationalen und soziologischen Grundlagen der Musik, trad. ital. cit., p. 67.

20. Cf. K. Blaukopf, «Tonsysteme und ihre gesellschaftlische Geltung in Max Webers Musiksoziologie», International Review of the Aesthetics and Sociology of Music, 1970, pp. 161-162. Ct. también K. Blaukopf, Musik im Wandel der Gesellscbaft, Munich, 1982, p. 178.

21. C. Stumpf, E. von Hornbostel, Uber die Bedeutung etnologischer Untersucbungen für die Psychologie und Ästbetik der Tonkunst, en Bericbt über den 4. Kongresse für experimentelle Psycbologie, Innsbruck, 1911, p. 264. El fragmento citado pertenece a la parte de Stumpf. 
pretensión normativa de la estética y legitimar la multiplicidad de las culturas estéticas y de los modelos respectivos. Sin embargo, Max Weber desea mantener apartado de su estudio cualquier problema relacionado con el «valor» estético. Con todo, no hay que olvidar que el punto de vista adoptado por el análisis es el del «hombre europeo moderno» y de la ratio burguesa, de modo que el interés del que brota la problemática está ligado a una óptica particular. $Y$ para la investigación esto supone una implicación que hay que tener en cuenta. ¿Hasta qué punto la originalidad de la música de Occidente, caracterizada en los términos antes mencionados, se mantiene como mera diferencia técnica sin adoptar el carácter de una excepcionalidad y de una supenioridad plena?

De la exploración de las implicaciones de Los fundamentos racionales y sociológicos de la música parece surgir un cuadro distinto del relativismo estético señalado por Stumpf. Metafóricamente hablando, se tiene la impresión de que en el discurso de Max Weber lo que a primera vista podría parecer una antropología cultural de la música va asumiendo una curvatura que la asimila más bien a una antropología diferencial, esto es, a la investigación de los elementos distintivos del ser humano respecto a los demás seres de la escala biológica. Se trata de un estudio comparativo, ciertamente, pero con vistas a la investigación y a la confirmación de la identidad cultural del propio mundo, incluso del musical. Es evidente que la reflexión weberiana tiene una frontera. Efectúa un reconocimiento más allá de las tradiciones musicales de Occidente, pero lo hace para recabar la confrrmación de una identidad. El conocimiento de la diversidad es demasiado preciso para que pueda plantearse un prejuicio eurocéntrico o eurocultural; pero al mismo tiempo, el sentido de la centralidad de la historia de la música culta occidental, aun sin ser nunca explicitado, no permite hablar de relativismo cultural. La sociología de la música no tiende a resolverse en etnomusicología, según un proyecto que tiene hoy numerosos partidarios. Además, la «cientificidad» de la construcción weberiana no excluye que la sociología de la música esté de algún modo abierta a horizontes precientíficos.

De acuerdo con tales premisas, quizá no sea casual que en las Lecciones de sociología, al cuidado de Horkheimer y Adorno para el Institut für Sozialforschung de Frankfurt, y precisamente en la sección dedicada al arte y a la música, el nombre de Max Weber esté asociado a la tradición del «gran arte» de Occidente: «La historia de la música es concebida por Weber en el seno del proceso de racionalización del mundo occidental, demostrando que sólo sobre la base de esta racionalización, es decir, del dominio progresivo sobre la naturaleza, se hace posible la elaboración por parte del hombre del material sonoro y, en consecuencia, el desarrollo de la gran 
música.» 22 sigue: «Weber ha situado el desarrollo estético inmanente de esta esfera artística en una correlación inteligible respecto del desarrollo general de la sociedad, $»^{23}$ En otro lugar habla Adorno de un «aspecto estético de la tesis de fondo de la sociología musical de Weber»:24 más significativo es todavía el hecho de que en uno de sus ensayos, Bach defendido contra sus admiradores, reivindique la plena participación de Bach en la cultura del iluminismo, incluso con un argumento de matriz weberiana: la tesis de que El clave bien temperado es «una obra que ya desde su título está de parte del proceso de racionalización». ${ }^{25} \mathrm{El}$ análisis weberiano del temperamento uniforme $\mathrm{y}$, más en general, su tesis sobre la penetración de la ratio burguesa también en el campo de la música, tienen fines críticos y se adaptan a la interpretación y a la ubicación de la obra de Bach.

¿Se trata de una arbitrariedad, de una trasposición ilegítima? No es ése el problema. El estudio -o mejor, el fragmento póstumo de Max Weber- dibuja una concepción de la música en cuyo centro se sitúa el modelo de la ratio burguesa. Que la crítica musical -esto es, una actividad proyectada hacia el sentido de la música, hacia su investigación e interpretación- encuentre útil servirse de instrumentos sacados de otros campos teóricos sólo se legitima por referencia al resultado. Si la sociología ofrece conceptos que pueden adecuarse a fines interpretativos, aunque en su origen hayan madurado en otros contextos, es evidente el interés de la crítica en apropiárselos. Pero la mutación, en este caso específico, viene propiciada por el hecho de que las páginas de Max Weber ofrecen una concepción de la música, un panorama que ya de algún modo está dotado de valores interpretativos, pues permite la referencia a aspectos concretos de la realidad musical o a obras y sectores de producción concretos dentro de un cuadro de referencia general. De hecho, el límite que la separa de la crítica o de una estética sociologizante no es infranqueable, y su «cientificidad» no representa un obstáculo en este sentido.

Los ejemplos aquí recogidos evidencian la presencia, en el interior de la vastísima galaxia «sociología de la música», de elementos atraídos del

22. M. Horkheimer, Th. W. Adorno (Hrsg.), Soziologische Exkurse, trad. ital. Lezioni di sociologia, Turín, 1966, p. 125 (existe trad. castellana: La sociedad. Lecciones de sociología, Buenos Aires, Proteo, 1969).

23. Ibidem.

24. Th. W. Adorno, Einleitung in die Musiksoziologie, trad. ital. cit., p. 256.

25. Th. W. Adorno, Bacb gegen seine Liebbaber verteidight, en Prismen. Kulturkritik und Gesellschaft, trad. ital. Prismi. Saggi sulla critica della cultura, Turín, 1972, p. 131 (existe trad. castellana: Prismas. La crítica de la cultura y la sociedad, Barcelona, Ariel, 1962). 
campo de gravitación de la estética y de la crítica. Particularmente de elementos relacionados con la confrontación entre la identidad estética autónoma del objeto musical y su valor social; o entre la identidad estética y su degeneración en la esfera del consumo de masas; o entre la identidad cultural ligada a los valores activos de una tradición y las culturas musicales de sociedades extranjeras. Sin embargo, ¿qué interés tienen hoy día este tipo de planteamientos? Kurt Blaukopf ha escrito recientemente que el imponente desarrollo de la etnomusicología «ha abierto los ojos y los oídos del musicólogo, no sólo hacia la antropología, sino también hacia la sociología»; ${ }^{26}$ y desde el mismo punto de vista ha observado que sería preferible hablar, más que de sociología «de la música», de sociología «de las músicas», subrayando la multiplicidad irreductible de los modos de ser de sus objetos. Hay que evitar particularmente el prejuicio que conduce a ver en la música un arte, pues el estatuto estético está muy lejos de agotar la complejidad y las innumerables modalidades de la experiencia musical. «Los estudios sobre la evolución de la música étnica europea, los estudios sobre la historia de la música europea premoderna, el análisis de la música de consumo mediada por la técnica de la moderna civilización industrial, y finalmente las investigaciones sobre la vida musical de las poblaciones extraeuropeas, muestran que el objeto de la indagación musicológica -y por tanto también el de la sociológico-musical- debe ser representado de modos diversos y más amplios. ${ }^{27}$ Efectivamente, no sólo el desarroIlo de la etnomusicología, sino también el refinamiento de su conciencia teórica, han contribuido a desmontar las exclusiones de que se alimentaba la cultura estética de la música. El diseño de una antropología musical que va tomando cuerpo hoy día representa también una instancia de apertura diametralmente opuesta a las orientaciones selectivas y «cualitativas» de dicha cultura. Además, la historiografía musical se muestra cada vez más conocedora de los límites de las construcciones tradicionales y cada vez más dispuesta a abarcar nuevos objetos de estudio. Podría añadirse que también la semiótica musical ha abierto nuevos horizontes, poniendo en evidencia factores de la comunicación musical no reducibles a una dimensión estética.

Así pues, la pluralidad ontológica del objeto musical encuentra en los nuevos desarrollos de la musicología apoyos teóricos cada vez más sólidos. La propia estética musical, entendida en una versión actualizada, esto es, no ya como apología o legitimación de un valor, sino como indagación científica sobre la génesis, la estructura y el perfil histórico de un paradig-

26. K. Blaukopf, Musik im Wandel der Gesellschaft, cit., p. 17.

27. Op. cit., pp, 17-18. 
ma, el estético, tiende a enfocar la relatividad cultural de la música como «arte» y como «obra». Es casi trivial recordar que también la producción musical contemporánea ha contribuido a la disgregación del paradigma tradicional de la «obra de arte». Paralelamente a todo ello - y en parte quizá como reflejo-, la experiencia musical común considera cada vez menos familiar y más retórica la mitología de la «gran música».

Frecuentemente, la tradición «especulativa» de la sociología de la música coincidía con una investigación de sentido estético efectuada también con categorías sociológicas. Por tanto, se concluiría espontáneamente que, así como hoy en día el paradigma estético (y con él la crítica, en la medida en que se propone como interpretación de objetos estéticos) vive una crisis radical, es evidente también que los presupuestos que sostenían tal modelo de la sociología de la música se han debilitado. Pero la crisis ya estaba presente en el interior del propio modelo. Hablar de experiencia del limite significa precisamente señalar un estado de malestar teórico originado por la fidelidad a un viejo mundo de valores todavía operantes, pero viciados y convertidos en problemáticos. En realidad, la radicalización de la crisis, la corrosión que actúa en la herrumbre retórica de los que fueron valores operantes para grupos sociales no muy vastos pero culturalmente influyentes y con frecuencia hegemónicos, no permite ya aquel armisticio del que era fruto, por ejemplo, la sociología adorniana de la música, encarnación emblemática de dicho problema. En otras palabras, el límite ha sido desplazado; la contigüidad con la esfera tradicional de lo estético se ha vuelto más bien distancia histórica, y la dialéctica entre autonomía y heteronomía no puede desarrollarse en ausencia de uno de los dos polos. Se ofrece así un punto de partida para una hipotética - pero digna de ser tenida en cuenta- sociología de la sociología de la música.

Quisiera terminar con una brevísima digresión. Quizá sea ésta la clave para la lectura, en general, de la parábola que ha conducido a la obsolescencia de la «teoría crítica de la sociedad» adorniana. Desde el momento en que los fenómenos sociales en ella prefigurados o descritos adquieren consistencia sólida, la teoría no gana, sino que pierde actualidad. La paradoja aparente se debe al hecho de que los propios fenómenos que la confirman neutralizan sus valores críticos, ligados a modelos culturales drásticamente cambiados. Por otra parte, cacaso la propia teoría no había en cierto sentido preconizado su propia derrota? 